\title{
Frágeis damas e mulheres fortes: a representação feminina na Restauração de Portugal (1640-1668)
}

\author{
Carlos Ziller Camenietzki** \\ Rejane da Conceição Meirelles ${ }^{* * *}$
}

\begin{abstract}
Resumo
Os escritores de Portugal não se furtaram a representar as mulheres portuguesas durante a Guerra da Restauração (16401668). Essas imagens, baseadas em escritos de época, se apresentavam aos leitores com um sentido bastante específico $e$ ligado aos objetivos dos diferentes partidários do golpe restaurador. Com o passar do tempo, elas mudam de significado $e$ acabam se integrando na pauta própria dos debates de cada época específica. Assim, para o tempo de agora, cumpre destacar o papel da combatente feminina desta guerra personalizado em Isabel Pereira, mulher de Ouguela.
\end{abstract}

Palavras-chave: Restauração de Portugal, Guerra contra Castela, Mulheres Combatentes, Fidalgas e Patriotas.

\footnotetext{
* Recebido para publicação em maio de 2007, aceito em janeiro de 2008.

** Doutor pela Université de Paris IV-Sorbonne, Professor de História Moderna da UFRJ. carlosziller@ifcs.ufrj.br.

*** Mestranda em História pelo Programa de Pós-Graduação em História Social da UFRJ.rejanemeirelles@yahoo.com.br.
}

cadernos pagu (30), janeiro-junho de 2008:373-394. 
Frágeis damas e mulheres fortes

Fragile Ladies and Strong Women:

the Feminine Representation in the Restoration of Portugal (1640-1668)

\begin{abstract}
Representing the different views opposing each other during the Restoration War (1640-1668), Portuguese writers were also talking about the women in their country. As time goes by, the meanings of these images of women change, and they are finally made a part of the specific historical agenda of this period. For our own time, the distinguished makings of the fighter Isabel Pereira, a woman from Ouguela, is discussed here.
\end{abstract}

Key Words: Restoration in Portugal, War against Castile, Women Fighters, Nobles and Patriots. 
Muitas vezes, em função de problemas e tensões do presente, atentamos a temas do passado em busca de argumentos que fortaleçam nossos pleitos. Com isso, ao escolhermos nesse nebuloso tempo pretérito a imagem mais adequada, trazemos com ela elementos secundários que não parecem ter efeito imediato na disputa de agora, mas que acabam por consolidar uma idéia do passado francamente contraditória com os testemunhos e os resíduos deixados por aqueles tempos.

Em trinta de maio de 1840, encenou-se em Lisboa uma peça que viria a se tornar célebre: Philippa de Vilhena (Almeida Garrett, 1846:30-105). Obra ambientada às vésperas do golpe que restaurou a independência portuguesa diante da Monarquia Católica de Castela, em primeiro de dezembro de 1640, ela contribuiu significativamente para a formação da imagem da mulher portuguesa durante a guerra que se seguiu entre o reino recém-liberto e seus anteriores governantes. É certo que D. Philippa de Vilhena, na versão de Almeida Garrett - autor do texto - não foi a única versão, talvez nem mesmo a mais importante sobre o feminino português e sobre seu empenho na defesa da pátria (sempre é bom lembrar que neste tempo havia cerca de trinta anos das invasões napoleônicas em Portugal). Porém, trata-se de peça de largo sucesso, encenada e editada diversas vezes, adotada nas escolas e celebrada em exposições $e$ mostras sobre a Restauração do reino. Por essa razão, cabe detida reflexão sobre ela, sobre a imagem feminina que busca consolidar e sobre seu confronto a documentos de época, tratando das mulheres portuguesas durante os vinte e oito anos dos combates.

A passagem tida como momento síntese da peça é a fala de D. Philippa enquanto "arma" seus dois filhos na madrugada do primeiro de dezembro de 1640.

Meus amigos e meus parentes, eu sou uma pobre viúva a quem Deus privou de toda a força e amparo n'este mundo (...) A pátria precisa de todos, tudo. Aqui estão meus filhos. Não tenho mais nada... - Meus filhos! Ajoelhai. Aqui estão 
Frágeis damas e mulheres fortes

no altar de Deus e da pátria... Vítimas inocentes e puras! Aceitai-as, meu Deus!... e dai-nos a vitória! Vão banhadas com algumas lágrimas, que se não podem conter no coração ... perdoai-mas, Senhor. Sou mãe, e estes são meus filhos. Senhores, é uma espada na mão de uma mulher que mal pode com ela. (...) Ajoelhai, meus filhos. Vossos avós foram armados cavaleiros nos campos de batalha por braços de reis com as espadas de grandes capitães. Vós, criancinhas, é vossa mãe, que ainda ontem vos acalentava, vossa mãe que lhe treme o braço, que lhe rebenta o choro nos olhos, que aqui está sustida d'uma força sobrenatural que ela mesma não compreende... Arma-vos vossa mãe, filhos, e sereis tão bons cavaleiros como os que vos precederam, porque eu tenho fé, porque chamo por Deus em cujo nome vos dou estas armas, e vos digo - D. Jerónymo de Ataíde, D. Francisco Coutinho, em nome de Deus e de vossos avós, eu vos armo cavaleiros. Tomai esta espada e não vos sirvais d'ella senão para defender a religião, a pátria, a liberdade do povo e os vossos legítimos reis. ${ }^{1}$

O trecho, que compõe uma obra de ficção - teatro - feita com fins comemorativos da Restauração da independência política, é efetivamente muito emotivo, forte, e demonstra a capacidade criativa de seu autor. Certamente, Almeida Garrett sabia perfeitamente que uma cena dessas nunca poderia ter lugar em Portugal de tempo algum. Armar cavaleiros apoiando a espada a seus ombros é um mote importante da Idade Média, vista pela literatura romântica do século XIX, mas é coisa que em terras lusas não faz o menor sentido, sobretudo para acontecimentos do tempo da Restauração. D. Philippa, que neste tempo contava já seus quase sessenta anos, é apresentada aqui como uma jovem e frágil senhora, ela que nada tinha de desprotegida: era viúva do Conde de Atouguia, mulher fidalga.

1 Cena VI, Segundo ato (pp.77-9 da edição que utilizamos). A peça foi encenada pela primeira vez em 30 de maio de 1840 no teatro Salitre de Lisboa. 
Seus filhos, D. Jerónymo de Ataíde e D. Francisco Coutinho, os "cavaleiros" na peça, representados como crianças intrépidas, contavam já com mais de vinte anos em dezembro de 1640; eram homens feitos e experimentados.

Mas o problema relevante nessa passagem não é a identificação das impossibilidades históricas ou de uma hipotética fidelidade ao passado. Neste ensaio, interessa identificar o modelo feminino que Almeida Garrett buscou fixar com esse trecho. Aqui, a personagem é imagem da fidalga que o romantismo português desejou cultuar: mulher frágil, porém decidida; mãe delicada, mas vigorosa e comprometida com os ideais da nobreza, capaz de lançar seus rebentos numa operação perigosa pela liberdade da pátria; alguém que mal pode segurar uma espada sem o concurso da Divina Providência.

$\mathrm{O}$ autor do texto certamente contou com o apoio decisivo do mais afamado historiador português da Restauração, D. Luís de Menezes, Conde da Ericeira, autor da conhecida História de Portugal Restaurado, publicada pela primeira vez em 1679. Nesta obra, Ericeira relata uma curta passagem sobre D. Philippa de Vilhena e seus filhos na madrugada do primeiro de dezembro. Os termos são os seguintes:

Preveniram-se e armaram-se todos, e foi muito para louvar o valor de D. Philippa de Vilhena, condessa de Atouguia, porque, fiando-se da sua prudência o segredo deste negócio, ajudou a armar seus dois filhos $D$. Jerónimo de Ataíde e D. Francisco Coutinho, e os exortou a conseguir a valorosa ação que empreendiam (Menezes, 1945:119).

Comparando a narrativa de um contemporâneo dos acontecimentos com o texto da peça do século XIX, não é difícil imaginar que a expressão "ajudou a armar" transformou-se em "armou cavaleiro", na apreensão do escritor romântico. Também não é impossível supor que o tema da Restauração - "restaurar, recompor o que se desfez" - tenha ajudado a inspiração de 
Frágeis damas e mulheres fortes

Almeida Garrett a retroceder a um tempo supostamente medieval, para compor sua imagem da Condessa de Atouguia, embora saibamos que esses rituais de sagração de cavaleiros em nada combinam com a conquistadora Idade Média portuguesa.

Mas o acontecido ganhou notoriedade. A passagem da História do Conde da Ericeira teve foro de testemunho privilegiado dos feitos da guerra e da política do reino durante os quase trinta anos do conflito. O ponto-de-vista de D. Luís de Menezes sobressaiu dentre os demais de seu tempo e a história fidalga da Restauração acabou por suplantar suas concorrentes. ${ }^{2}$ É verdade que, no que respeita à passagem relativa a $\mathrm{D}$. Philippa, os testemunhos não andavam muito diferentes, conforme pode ser visto no livro de Giovanni Battista Birago, escrito por instância de D. Vasco Luís da Gama, Marquês de Niza e então embaixador de D. João IV na França. ${ }^{3}$ Outro testemunho do século XVII, de Alessandro Brandano, também escritor fidalgo, este a serviço de D. Pedro II, aproveita para lembrar a "incapacidade" do sexo feminino em sua narrativa dos acontecimentos daquela madrugada. ${ }^{4}$ Um tanto mais generoso, o Abade Vertot, em sua

2 A restauração da independência portuguesa foi objeto de inúmeras obras históricas do século XVII. De fato, um acontecimento político europeu de tanta importância, já tido como marco do declínio espanhol no tenso equilíbrio do continente, não poderia deixar de atrair as atenções. Não apenas por isso, mas as reviravoltas do governo português durante o reinado de D. Afonso VI e as suas inúmeras peripécias diplomáticas também foram objeto de forte interesse e de intensa disputa.

3 "Em cuja glória entram as mesmas damas tão animosas que armaram seus próprios filhos e irmãos, para que fossem libertar a pátria. Tal foi $\mathrm{D}$. Philippa de Vilhena, Condessa de Atouguia, que na mesma manhã que devia seguir a aclamação, armou com suas próprias mãos o Conde D. Jerônimo e D Francisco Coutinho, seus filhos animando-os a ir e realizar conforme convinha ao seu nascimento, lamentando não poder acompanhá-los naquela ocasião com o corpo como os acompanhava com a vontade". (Birago, 1647:185-6).

4 "Foi coisa bastante notável e digna de ser eternamente guardada pela memória dos vindouros que na noite que precedeu a um tão maravilhoso acontecimento, as principais damas e matronas partícipes da planejada revolução animaram, contra o costume da imbecilidade daquele sexo, com eficazes emulações os 
Carlos Ziller e Rejane Meirelles

primeira obra, caracteriza a participação de D. Philippa de Vilhena de modo mais dramatizado, incluindo uma hipotética fala da condessa a seus filhos. ${ }^{5}$

António de Sousa de Macedo, secretário da embaixada à Inglaterra nos primeiros tempos do governo de D. João IV, empenhado escritor político da Restauração, futuro Secretário de Estado no governo de Castelo Melhor, sob Afonso VI, também deixou registro da ação de $\mathrm{D}$. Phelippa. Seu livro foi publicado em Londres ainda em 1645 e Sousa de Macedo trata do empenho feminino na madrugada do primeiro de dezembro em termos pouco dramatizados, porém não menos entusiasmados. ${ }^{6}$ Porém, a referência que mais importa aqui citar é aquela de João Pinto Ribeiro, importante organizador do golpe restaurador e importante político dos primeiros anos da independência recuperada. Diz ele:

Mais que muito, pois aquele generoso espírito de Dona Philippa de Vilhena, ilustre Condessa de Atouguia, armou por suas mãos, naquela manhã a seus filhos, o Conde D. Jerónimo de Ataíde, \& D. Francisco Coutinho, animandoos a obrarem como quem erão, em serviço de sua pátria, \&

maridos e os filhos à realização da empreitada, ajudando-os a vestir as armas que deveriam empregar para a comum libertação da sua Pátria". (Brandano, 1689:53).

5 "Diversas mulheres quiseram participar da glória desta jornada. A História conserva a memória de D. Philippa de Vilhena, que armou com suas próprias mãos seus dois filhos; e após lhes ter dado suas couraças: 'ide meus filhos, lhes disse ela, acabar com a tirania, e nos vingar de nossos inimigos e estejais seguros que se o desfecho não corresponder a nossas esperanças, vossa mãe não sobreviverá um só instante ao sofrimento de tantas pessoas de bem"' (Vertot, sd:88-9). A obra foi editada pela primeira vez em 1689 com o título de Histoire des Conjurations du Portugal.

6 "Digníssimo de memória é o que fizeram D. Philippa de Vilhena, Condessa de Atouguia, e D. Antónia da Silva, filha de D. Antão d'Almada que armaram com suas próprias mãos seus filhos; aquela o Conde D. Jerônimo e D. Francisco, esta D. Luís da Cunha; e armados foram conclamados generosamente a lutar pela liberdade: a vida mais miserável bem pode se transformar na morte mais digna" (Macedo, 1645:561-2). 
Frágeis damas e mulheres fortes

da liberdade de todos, sentida \& invejosa de os não poder acompanhar naquele ato, como os acompanhava na vontade e no valor (Ribeiro, 1730:31). ${ }^{7}$

Conforme se pode ver facilmente, a imagem da mulher fidalga portuguesa de Almeida Garrett em nada se parece com aquela deixada pelos seus contemporâneos e pelos historiadores do século XVII. ${ }^{8}$

Contudo, a fidalguia é apenas parte do problema que nos ocupa. Bem mais interessante que o ato da Condessa encorajando seus filhos $e$ as interpretações dos tempos posteriores sobre este acontecido são os testemunhos da ação efetiva das portuguesas nas vilas $e$ nas cidades em que o conflito militar realmente ocorreu. Aqui, é claro, trata-se de outro tipo de mulher: nenhuma mulher fidalga participou de qualquer combate na fronteira, não houve Jeanne D'Arc nas zonas do conflito luso-castelhano de 1640-1668, não houve comandante militar feminino que tenha sido registrado pelos testemunhos que nos restaram. Porém, cabenos lembrar que nem só de fidalgos são feitas as crônicas $e$ histórias da Restauração e nem só de fidalgas são feitos os registros do passado. Aldeãs, camponesas, burguesas, freiras $e$ muito mais estiveram presentes no conflito e certamente o registro de seus feitos - ainda que poucos - pode revelar elementos importantes da condição feminina na guerra, nesta guerra.

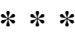

\footnotetext{
7 A primeira edição deste livro data de 1642. O trecho de Birago, citado acima, é praticamente uma tradução desta passagem de João Pinto Ribeiro.

8 Outros escritores da Restauração também tratam do feito de D. Philippa praticamente nos mesmos termos que os citados, e por isso dispensam referência direta no presente texto. Chamo a atenção apenas para a obra de Passarelli (1684) por sua difusão no norte da Europa. Contudo, é importante lembrar que nem todos os publicistas da Restauração registraram o feito de D. Philippa, vejase a ausência eloqüente de qualquer referência a ela no texto de Maia de Azevedo (1641).
} 
A Guerra da Restauração da independência de Portugal foi travada no terreno bélico propriamente dito, tal e qual toda guerra, com enfrentamentos militares na fronteira, etc., mas também no publicismo, no debate jurídico e na diplomacia. Inúmeros escritores de Portugal se lançaram em manifestos, histórias e em relatos sobre a evolução do conflito; os castelhanos, é claro, também fizeram o mesmo e ambos mobilizaram escritores de diversos países da Europa. A Restauração de Portugal foi, de fato, um dos grandes acontecimentos do Velho Mundo no século XVII.

Para o que interessa no momento dentre todo esse material impresso, as relações de guerra são capazes de ajudar a compreender a condição feminina neste processo. Eram estas relações textos curtos que narravam acontecimentos do confronto. Seus autores, na imensa maioria não identificados, eram homens que acompanhavam as tropas - militares, secretários, encarregados, etc. - e registravam as proezas dos portugueses nas fronteiras, ou escritores do governo que reelaboravam o material relatado na frente de combate. Dada a quantidade de relações e sua distribuição ao longo dos quase trinta anos do conflito, podemos dizer que formam um conjunto bastante expressivo daquilo que se desejava fazer crer sobre os combates e sobre a atitude dos portugueses. Afinal, esses textos eram escritos a partir de registros da fronteira $e$ impressos para circulação e leitura nas cidades e nas vilas do reino.

As relações foram publicadas durante todo o período da guerra, mas elas são mais abundantes no início do confronto (1641-1645) e, nesta fase, as ações das mulheres aparecem com maior freqüência. Há, nessas primeiras publicações, uma forte preocupação por parte de seus autores em expressar a galhardia e a determinação de todo o povo português, incluindo as mulheres, na luta pela restauração da independência política; note-se também que elas buscam enaltecer a ação dos capitães e dos mais novos chefes militares que agiam nas escaramuças e nos conflitos. 
Frágeis damas e mulheres fortes

Ao passo que, nas últimas, o relato fica bem mais restrito ao desempenho dos soldados e dos grandes chefes militares.

No momento, interessa a peculiaridade da ação das mulheres e o modo de sua participação nas batalhas. Percebe-se facilmente que aquelas que estão presentes nos acontecimentos não são passivas nem fracas, tampouco apenas encorajam os homens; ao contrário, elas são retratadas exercendo um papel importante e ativo nos campos de batalha. Mulheres destemidas, dotadas de consciência do dever patriótico e da coragem comumente conferida apenas aos homens são características detectadas sem muito esforço nas relações. São-nos oferecidas, pelas penas dos autores, descrições de enfrentamentos em que bravas e corajosas mulheres ofereciam a vida pela independência de Portugal. Em uma das relações encontra-se a seguinte passagem sobre uma mulher, que bem ilustra isso:

Achou-se nesta ocasião em Ouguella uma mulher tão varonil, que saiu com um chuço às trincheiras e entre os nossos soldados ajudou a resistir ao inimigo, como qualquer entre eles, e afirma-se, que dos que mataram foram alguns por sua mão, feriram-na na cabeça $e$ querendo os nossos recolhê-la para se curar, o não consentiu, antes perseverou animosa, pelejando com mais irritado valor. ${ }^{9}$

9 Relaçam dos gloriosos sucessos, que as armas de Sua Magestade El Rey D. Joam IV N. S. tiverão nas terras de Castella, neste anno de 1644 até a memorável Victoria de Montijo. Anno 1644. Lisboa, António Alvarez, 1644, p. 7 e 8. O folheto encontra-se na Coleção Diogo Barbosa Machado, Notícias dos sucessos militares, Tomo II, 1643-1653. Dada a natureza desses impressos, sua localização nas bibliotecas de Portugal é muito difícil. Contudo, o bibliófilo Barbosa Machado recolheu uma grande quantidade delas e as organizou em cinco grossos volumes de sua coleção. Seguimos a numeração das páginas desta coleção e assinalamos ao final da referência o volume em que se encontra o texto. 
Além do já citado louvor à atitude de uma mulher no combate, chama a atenção o inaudito modo como ela adentrou no universo bélico: de sua própria iniciativa. Tornam-se soldados as mulheres por um ato corajoso, inesperado e, sobretudo, voluntário. $\mathrm{E}$ mais do que isso, soldado valoroso que matou alguns inimigos com sua arma $^{10} e$, mesmo ferida, ainda mais vigorosamente combateu e mostrou seu valor. É curioso reter ainda que o nome da mulher não é apresentado: uma anônima inesperada invade a cena e, com sua fúria, chama a atenção do leitor.

Mas os escritores das relações, neste particular, não se limitaram à descrição de proezas femininas durante a peleja nem ao registro de sua curiosa inserção por iniciativa própria. Além de abundantes narrativas heróicas sobre as mulheres no front, há relações em que os autores buscam enaltecer o procedimento diferenciado de suas compatriotas por intermédio de referências histórico-literárias, buscando em antigas crônicas romanas $e$ portuguesas uma ilustração do valor das mulheres portuguesas. $\mathrm{O}$ passado confirma a ação heróica das mulheres de Portugal. Especificamente nessa relação, busca-se na literatura histórica a lembrança de mulheres que voluntariamente se tornaram elementos eficazes nas batalhas de outrora, tendo como elemento fundamental a atitude heróica de cada uma delas:

Aqui vemos renovadas as façanhas não só dos homens, mas ainda das mulheres Portuguesas, de que fazem menção as Crônicas Romanas $e$ as nossas. Porque aqui andaram as mulheres no meio do conflito ajudando aos maridos e carregando-lhes os arcabuzes, para os descarregarem no Castelhano, a que fizeram retirar, deixando às nossas vistas duzentos infantes mortos. Não foi menor o zelo de uma mulher do mesmo lugar, que vendo

\footnotetext{
${ }^{10}$ Embora a palavra "chuço" ainda esteja em uso, seu significado mudou muito nos últimos quatro séculos. Raphael Bluteau, no seu vocabulário, assegura que se tratava de arma corrente nos combates do século XVII - uma espécie de lança (Bluteau, 1712:304).
} 
Frágeis damas e mulheres fortes

entre os inimigos um tio seu, que daquele lugar se passara fugitivo para Castela, e tornava contra sua pátria, lhe atirou com uma pedra, de que o matou, mostrando que quem negava sua pátria, os mesmos parentes por honra sua lhe deviam dar a morte. ${ }^{11}$

A passagem mostra que a mulher em questão agiu seguindo uma hierarquia de valores bastante específica e surpreendente quando se considera que o episódio teria ocorrido em meados do século XVII, em plena ascensão do que é chamado de "Antigo Regime". A pátria situa-se no topo da hierarquia com o valor máximo, sobrepondo-se inclusive à estrutura familiar $e$ ao parentesco mesmo nas situações mais delicadas. Diante da escolha entre imolar a vida de um ente familiar e cumprir um dever patriótico, ou proteger um parente e compactuar com a traição à pátria, a primeira opção é a que deve ser tomada, e é aquela que foi adotada pela anônima mulher da fronteira de Almeida. Quer o escritor convencer seus leitores, em 1642, de que a própria família pode ser sacrificada em virtude do bem-estar $e$ promoção da pátria; e mais, de que o agente deste sacrifício é uma mulher!

O ideal romano de pátria, descrito por Cícero e certamente muito conhecido dos autores lusos do século XVII, parece relevarse nesta situação: "prefira-se a salvação da Pátria à conservação do pai" (Caneca, 2001:90). Também Tito Lívio, outro autor bastante cultuado em toda a Europa daquele tempo, parece ter seu mote confirmado pelas lusas da Restauração: "o cidadão virtuoso tem a República em maior preço do que os parentescos particulares" (Id. ib.). Essa reflexão, expoente da firme posição no que tange ao amor à pátria, ultrapassou tempos e mares. Até no século XIX, essas citações romanas foram empregadas por Frei

${ }^{11}$ Facçoens venturosas que tiverão na fronteira de Almeida o General Fernão Telles de Menezes, \& o Mestre de Campo D. Sancho Manoel, contra o inimigo castelhano, em 2. \& 4. deste mes de Novembro do anno presente 1642. Lisboa, Domingos Lopes Rosa, 1642, p. 8. Barbosa Machado, op. cit., Tomo I:352. 
Carlos Ziller e Rejane Meirelles

Caneca, em meio às discussões relacionadas com as disputas políticas entre os governos provinciais e o governo central no império brasileiro. É certo que a "pátria" da portuguesa da fronteira e aquela do escritor da relação não é a mesma de Cícero ou de Tito Lívio, ou ainda aquela de Frei Caneca e dos escritores do século XIX, contudo, firma-se o parâmetro, e sua projeção em todo o Ocidente contemporâneo e moderno é claramente perceptível: "à pátria tudo".

A participação feminina nas guerras do século XVII não se restringia à costumeira condição de vítima preferencial da ferocidade dos vencedores ou de fonte de insegurança dos seus combatentes. Durante a investida galega de 1658 no Minho, norte de Portugal, uma pequena passagem do Conde da Ericeira sobre o cerco de Lapela nos evidencia esse último papel reservado às mulheres: o terror incutido nos soldados pela visão dos cadáveres e pela aflição das mulheres e das crianças provoca a rendição indevida do governador português. ${ }^{12}$

Além dessas participações, diversas mulheres acompanhavam os conflitos em condições variadas: seguiam as tropas guardando os frutos dos saques, cuidando dos filhos e do material de seus companheiros; para os soldados "profissionais" nas guerras prolongadas, cozinhavam e preparavam o material bélico, carregavam as armas de fogo ligeiras (arcabuzes, etc.) $e$ realimentavam combatentes, cuidavam dos feridos. Em batalhas de defesa, como a maior parte daquelas retratadas nas relações que estudamos, participavam dos feitos como resistentes

12 "Governava Lapela Gaspar Lobato de Lançóis, soldado de valor, porém, mais carregado de anos que de experiências, o que logo se começou a verificar, admitindo no castelo muitas mulheres e meninos que costumam ser incentivos da pouca constância dos soldados na defesa das praças"... mais adiante, Ericeira confirma seu parecer... "Gaspar Lobato, perturbado do clamor das mulheres e meninos, e assombrado do horror dos mortos e ameaço dos galegos, fez chamada e se rendeu com cento e cinquenta soldados, três peças de artilharia, quantidade de munições e bastimentos com que pudera defender o castelo muitos dias" (Menezes, 1945 [1679]:168-9). 
Frágeis damas e mulheres fortes

defensoras de suas cidades e aldeias e, na menos marcante das atuações, guardavam e protegiam as crianças.

Do modo tratado no presente estudo, diante do testemunho quente dos combates, não é possível considerar o feito bélico apenas como proeza daqueles que se enfrentaram com as armas em punho, buscando uma vitória de grande significado. Por mais que queiramos, não nos é possível ver uma guerra prolongada apenas como arranjo de fidalgos em busca de promoção. E, nessa guerra lenta e combatida mais em escaramuças que em grandes $e$ retumbantes batalhas, diversas mulheres se apresentam como valorosos e vigorosos soldados.

No cerco de Monção, efetuado pelas forças de Castela entre outubro de 1658 e fevereiro de 1659, o empenho feminino na defesa da cidade ganhou destaque na obra do conde da Ericeira. Referindo-se aos momentos finais do cerco, pouco antes da sua rendição aos galegos, diz ele:

...sendo tantos os mortos e os feridos, que faltava quem guarnecesse os postos mais importantes, e até nas mulheres faziam lastimoso emprego. Governava as trinta que ficaram na praça, Helena Peres, mulher que havia sido de João Filgueira, com um chapéu na cabeça e um chuço nas mãos conduzia as outras aos maiores conflitos, sem se conhecer em alguma delas o menor indício de temor (Id. ib.:238).

O conde certamente não dissimula suas expectativas quanto ao desempenho militar das mulheres e menos ainda aquilo que considerava ser seu lugar efetivo numa frente de combate. Contudo, o registro da ação bélica das trinta mulheres de Monção chegou até nós e ele também colocou seus feitos na seqüência histórica lembrando que é "... timbre de todas as mulheres de Monção imitarem Deusadeu Martins...", lendária figura das guerras passadas entre portugueses e castelhanos na região. Com esse registro, Ericeira também contribuiu para consolidar mitos regionais lusitanos sobre as mulheres minhotas, ativos ainda hoje, no século XXI. 
Também não passou despercebida ao conde da Ericeira a colaboração da condessa de Castelo Melhor nos combates de seu marido, governador das armas do Minho e pai de Luís Vasconcelos e Sousa, futuro Escrivão da Puridade poucos anos depois. D. Mariana de Lencastre teria enviado cento e cinqüenta soldados em socorro do conde, contudo "...foram sentidos $e$ desbaratados mostrando o varonil espírito da condessa, que até nas desgraças da guerra acompanhava fielmente a seu marido" (Id. ib.:169). Claro fica, ainda, que o historiador apreciava bem pouco o Conde de Castelo Melhor e menos ainda seu filho, com quem viveu difícil confronto nos anos seguintes.

Em algumas ocasiões, a mulher chega a ocupar o papel principal no teatro das operações. No combate, elas eram soldados impávidos, causando baixas ao inimigo mesmo diante dos reveses mais inesperados. Na logística, eram ajudantes eficientes. Na pátria, símbolo de coragem:

E sobre todos se realçou o feito da outra mulher, que na mesma vila matou por detrás de uma porta com uma cachaporra sete castelhanos, imitação da celebre forneira de Aljubarrota, mas menos venturosa no sucesso, pois com dois piloros a mataram por cima de um telhado. E depois de morta foi achada com uma criança de peito mamandolhe nos seus. Fazem menção destas façanhas, porque se veja que com as ocasiões ressuscitam os brios nos Portugueses, e que com razão disseram os Castelhanos nesta ocasião, que quatro sebosos Portugueses haviam burlado de toda Castela. ${ }^{13}$

Arma comum nos combates daquele tempo: o porrete. Dele se serviu uma mulher com tal eficácia que deu morte a sete castelhanos. Defendia sua aldeia esta mulher que teve por paga do seu feito a morte por balas inimigas. Imagem forte ainda mais reforçada com a notícia de ter sido achada morta com uma

${ }^{13}$ Facçoens venturosas... op. cit.:8. 
Frágeis damas e mulheres fortes

criança mamando-lhe os peitos. Mais feminino que isso, difícil encontrar.

Contudo, não se trata aqui de verossimilhança, ademais, depois de baleada com dois pelouros, não é de se crer que possa estar em condições de amamentar, ainda que ela tivesse filho pequeno. Trata-se de uma imagem oferecida ao público vivo $e$ afastado da frente de combate, aos leitores de Lisboa, de Coimbra, de Évora e das demais cidades distantes dos combates: o heroísmo desta mulher, que após participar com sucesso do enfrentamento, morre nutrindo uma criança aos peitos. Novamente é mulher sem nome, cuja marca de distinção é a própria morte, é mulher portuguesa, grosseira, que combate com um cacete e que cria eficácia com seu vigor e empenho. Narrar esse episódio é cumprir o programa anunciado logo a seguir na mesma citação: fazer renascer o brio português, fazer engajar na guerra de Restauração todo o povo de Portugal. Aparentemente, nada impedia os escritores no seu firme labor pela independência política do reino.

Bastante freqüente, o recurso aos feitos das portuguesas do passado remete o leitor à origem da inquietação portuguesa no conflito ibérico: restaurar. Afinal, os inssurretos de primeiro de dezembro e seus seguidores queriam repor um passado glorioso em presente, no seu presente. Então, relatar essas heróicas participações femininas no confronto pela independência aproxima e relembra os feitos celebrados em textos históricos, muito difundidos em Portugal daqueles anos. Para ficarmos apenas em uma obra histórica citada diversas vezes nos textos da Restauração, tomemos a Ásia de João de Barros e de Diogo do Couto. Como sabemos, essa obra clássica da literatura portuguesa foi escrita a mando real por historiadores escolhidos entre os humanistas de maior renome na época. Trata-se de obra vultosa organizada em décadas, segundo o modelo do romano Tito Lívio. 
Pretendeu-se com esse trabalho registrar e celebrar as glórias das conquistas portuguesas no Oriente. Sua leitura no início do século XVII não podia deixar de trabalhar os espíritos mais vivos no sentido de exaltar a condição perdida com a incorporação do reino à coroa de Castela, em 1580.

As relações da guerra da Restauração também utilizaram as Décadas de Diogo do Couto para lembrar e fortalecer a galhardia da mulher portuguesa nas lutas do reino. Em 1641, quando de um dos diversos cercos de Olivença, o escritor da relação aproveita-se do material histórico da quinta década para enaltecer o valor das mulheres durante um ataque inimigo:

Não merecendo menos as mulheres, que com grande animo ocupavam as trincheiras, asssoviando-lhe pelos ouvidos espessas nuvens de pelouros, as não podiam lançar fora, pedindo licença para com sombreiros guarnecerem as trincheiras mais faltas de gente, renovando a memória das antigas Portuguezas Anna Fernandes, \& Isabel da Veiga, que no primeiro Cerco de Dio sustentado pelo grande Antonio da Silveira, obraram as maravilhas que Diogo Do Coutto na sua quinta Decada relata. ${ }^{14}$

O episódio em questão, da Ásia (Couto, 1979:405), está exposto quando o autor relata o primeiro cerco de Diu, de 1538. É uma passagem um tanto pitoresca em que uma mulher confunde um soldado português desfigurado por queimaduras e ferido gravemente, com um turco prisioneiro. Ela tenta bater na cabeça com uma gamela e, sendo impedida, vai protestar veementemente com o comandante pedindo-lhe que a deixe agredi-lo. Sua reação, no texto de Diogo do Couto, é típica de quem não hesita em cumprir o dever de eliminar aqueles que obram contra o sangue português. Ela teria dito ao capitão:

${ }^{14}$ Relaçam verdadeira da milagrosa vitctoria que alcançarão os Portugueses, que assistem na Fronteira de Olivença, a 17 de Setembro de 1641. Lisboa, Jorge Rodrigues, 1641, p. 7. Barbosa Machado, Tomo I:58. 
Frágeis damas e mulheres fortes

Como mandais vós, senhor, dar vida a uns inimigos que tanto têm trabalhado para nos beber o sangue? Se tal é verdade, eu, e estas minhas companheiras que neste cerco temos tamanho quinhão, como todos os homens, o não havemos de consentir, antes os havemos de espedaçar com nossas mãos, por isso mandai que no-los entreguem (Couto, 1779:405).

Bravura incontida da moradora da cidade cercada pelos inimigos, empenhada na sua defesa, tal e qual os homens, mas cujo excesso produz certa comicidade. Diogo do Couto registra a passagem dessa mulher não sem relatar diversos outros episódios em que as mulheres portuguesas de Diu mostram seu valor e sua eficácia durante os combates. Bem mais do que relatar um ocorrido, esse apelo histórico encaixa-se perfeitamente no programa restaurador, buscando revolver o "brio português", um tanto abalado pelos quase sessenta anos de domínio castelhano sobre o reino.

Nunca é demasiado lembrar que durante um bom tempo da guerra, Portugal foi governado por uma mulher, aliás, castelhana. Com a morte de D. João IV em 1656 e com a menoridade de D. Afonso, D. Luísa de Gusmão, rainha e esposa de D. João, assumiu a regência do reino e dirigiu o governo lusitano durante seis anos, inclusive durante momentos cruciais do conflito: perda de Olivença, batalha de Elvas, etc. A rainha era natural da Andaluzia, irmã do Duque de Medina Sidónia.

$\mathrm{O}$ fato de se viver sob o comando de uma mulher, aparentemente, não interferiu de modo substantivo no desenrolar dos acontecimentos na fronteira, ao menos pelo que registram as relações de guerra deste período. Contudo, os relatos não deixaram passar em brancas nuvens o comando feminino das armas de Portugal. Em Aronches, quando de uma investida inimiga que aprisionou mais de vinte portugueses, os castelhanos provocavam os portugueses cantando os versos seguintes: "o nosso rei he hum cravo, a rainha huma rosa, se não fora 
castelhana, inda fora mais fermosa" ${ }^{15}$ Desnecessário dizer que a crônica registra o desbaratamento da tropa pelos portugueses: os inimigos pagaram sua ousadia com o próprio sangue.

Imbuídas de determinados sentimentos e ideais que têm por objetivo a defesa do reino, as mulheres dos relatos de guerra são tão capazes de realizar feitos heróicos quanto os homens. Nesse processo, mesmo que também apareça uma referência genérica a uma fragilidade feminina, ela fica eclipsada pela pujança patriótica, o próprio relato a contradiz. A suposta, ou esperada, fraqueza da mulher quase sempre aparece pela sua negação, apoiada nos feitos considerados pelos autores suficientemente importantes para serem registrados nas narrativas e retidos pelos seus leitores. $\mathrm{O}$ trecho que se segue, retirado de uma relação sobre os feitos portugueses no cerco de Ouguela em 1644, demonstra bem esse fato, já apresentado em outra citação mais acima:

Mataram mais um soldado Português, feriram dois, e uma mulher por nome Isabel Pereira, que fará esquecer o valor das formosas Portuguesas, que nos insignes Cercos de Dio, \& Mazagão fizeram feitos de imortal memória, porque desmentindo esta a fragilidade do sexo feminino, fez notáveis demonstrações de valor, assim pelejando nas trincheiras, como repartindo pólvora, e balas aos soldados, $e$ retirada ao castelo ficou desacordada por algum espaço com a ferida que lhe deram, até que tornando em si, e vendo que não era perigosa, prosseguiu a peleja com maiores brios até o fim. ${ }^{16}$

\footnotetext{
${ }^{15}$ Relaçam de hum successo notavel, que teve huma companhia nossa de cavallos junto a villa de Aronches pelejando com o inimigo em 29 de dezembro de 643. Lisboa, Paulo Craesbeck, 1644:sn.

${ }^{16}$ Relaçam da famosa resistencia, e sinalada vitoria, que os Portugueses alcançarão dos Castelhanos em Ouguela, este Anno de 1644 a 9 de Abril governando esta Praça o Capitão Pascoal da Costa. Lisboa, Paulo Craesbeck, 1644, p. 6. Barbosa Machado, Tomo II:125.
} 
Frágeis damas e mulheres fortes

Aqui, a mulher em questão tem nome, Isabel Pereira, e não tem marido, e suas proezas nas trincheiras e na preparação $e$ distribuição do material de combate aparecem como feitos comuns a todos os soldados em qualquer batalha. Aqui não se trata mais de uma mulher valorosa e excepcional que realiza proezas extraordinárias: mata diversos inimigos com um porrete, ameaça com uma gamela, ou ainda que atira pedras. Isabel combate pela sua cidade, pela independência de seu reino, tal $e$ qual os demais moradores de Ouguela. Sua entrada na História das guerras da Restauração vem somar aos feitos masculinos, num terreno predominantemente masculino, o empenho presumido das mulheres de Portugal na defesa do reino recém-liberto do domínio político da mais poderosa monarquia daqueles anos.

Com isso, e sem desejar acumular mais referências e notas, cumpre refletir sobre o feminino nesta guerra que consumiu boa parte das energias e das riquezas ibéricas.

Contudo, seguindo a tensão entre os modelos de mulher propostos pelos escritores aqui rapidamente escolhidos, cumpre destacar que não faltaram mulheres nos relatos da guerra da Restauração. Para o escritor romântico do século XIX, Almeida Garrett, a mulher portuguesa que importa destacar encontra seu modelo na D. Philippa de Vilhena, condessa de Atouguia. Sua escolha, conforme vimos, tem amparo nos mais destacados escritores da época barroca que se dedicaram ao problema da conquista da independência de Portugal. A atitude do autor da famosa peça denuncia claramente aquilo que ele buscava modelar, não para a sociedade portuguesa do século XVII, mas para o seu próprio tempo vivido: $\mathrm{D}$. Philippa, mulher fidalga.

Nada nos impede, embora sem o brilhantismo de Garrett, de tentar um outro modelo feminino para as mulheres portuguesas daquele tempo: Isabel Pereira. Esta é mulher que combate efetivamente nas trincheiras, que reparte a pólvora, distribui alimentos etc. Ela não aparece apenas no início do 
esforço libertador, Isabel defende sua terra, sua gente e sua pátria contra aqueles que a querem ver submissa. Ferida, ela se reergue e continua seu combate até o final. Sua participação se estende por toda a fronteira e se apresenta em todos os anos do enfrentamento, em todos os combates. D. Pereira não é frágil e não faz valer suas capacidades nos palácios da Capital, não se realiza pelos atos de seus filhos; aliás, pouco importa se tem filhos, se é viúva. Ela empunha a arma que está a seu alcance (porrete, pedra, espada, espingarda etc.), e tem forças para isso. Ela o faz sem o auxílio da Divina Providência.

Escolher entre D. Philippa de Vilhena e Isabel Pereira o modelo feminino da Restauração: eis o problema!

$\mathrm{Na}$ primeira, encontramos apoio num texto forte de um dos escritores de maior prestígio de Portugal em meados do século $\mathrm{XIX}$, autor comprometido com os valores da fidalguia de seu tempo. Com ela se vai construindo uma mulher num tempo longínquo que apenas mostra sua eficácia para as mulheres vivas de hoje: a tradição nos dá uma mulher frágil e nobre, mãe patriótica e zelosa de seus filhos, capaz de desempenhar as funções masculinas, que não lhe são próprias, com a ajuda da Divina Providência, se a ocasião assim o exigir. A condessa de Atouguia, modelo feminino de Almeida Garrett, nos lega, assim, a imagem cômoda de um inimigo fácil de abater na construção da igualdade entre os gêneros. Inimigo tão frágil quanto o personagem do teatro, embora determinado e renitente, ela persiste no cenário das discussões sobre o feminino tal e qual persiste o fidalgo entre nós, os vivos do século XXI.

Isabel Pereira, modelo de mulher igualitária, foi abandonada pelas letras de língua portuguesa. Mais parece que temos medo do passado vivenciado por ela, tamanho esquecimento lhe legamos. Mas isso fomos nós que o fizemos, nós a abandonamos. Nós a trocamos por uma imagem mais cômoda de celebrar e de combater.

Mais firmemente ancorada na literatura, sua oposta lhe venceu todos os combates de que não participou e Isabel perdeu 
Frágeis damas e mulheres fortes

todos aqueles travados sem a sua presença, três séculos ou mais depois de sua morte.

\section{Referências bibliográficas}

Almeida Garrett, J. B. da S. L. de. Philipa de Vilhena. In: Obras, vol. VII. Lisboa, Imprensa Nacional, 1846.

Birago, Giovanni Battista. Historia della disunione del Regno di Portogallo dalla Corona di Castiglia. Amsterdam, Nicolau van Ravesteyn, 1647.

BluteAU, Raphael. Vocabulario Portuguez e Latino. vol. I, Coimbra, 1712.

BRANDANO, Alessandro. Historia delle guerre di Portogallo. Veneza, Paolo Baglione, 1689.

CANECA, Joaquim do Amor Divino. Dissertação sobre o que se Deve Entender por Pátria do Cidadão e Deveres deste para com a Mesma Pátria. In: Mello, Evaldo Cabral de (org). Frei Joaquim do Amor Divino Caneca. São Paulo, Editora 34, 2001.

CouTo, Diogo do. Ásia. Quinta Década, Livro IV, cap. 13, Lisboa, Regia Officina Typografica, 1779.

MACEDO, António de Sousa de. Lusitania Liberata ab Injusto Castelanorum Dominio. Londres, Richard Heron, 1645.

MAIA DE AZEVEDO, Nicolau da. Relação de tudo o que se passou na felice aclamação do mui alto e poderoso Rei $D$. João o Quarto nosso Senhor, cuja monarquia prospere Deos por largos annos. Lisboa, Lourenço de Anvers, 1641.

Menezes, Luís de (Conde da Ericeira). História de Portugal Restaurado. vol. I, Porto, Civilização, 1945 [1679].

PASSARELLI, Gaetano. Bellum lusitanum ejusque regni separatio a regno castellensi. Lyon, J. Posuel et C. Rigaud, 1684.

RIBEIRO, João Pinto. Usurpação, Retenção e Restauração de Portugal. In: Obras Várias, vol II. Coimbra, José Antunes da Silva, 1730 [1642].

Vertot, Réné Auber de. Histoire des Révolutions de Portugal. Paris, Borrani, sd. 